\title{
Current and Prospective Li-Ion Battery Recycling and Recovery Processes
}

\author{
JOSEPH HEELAN,${ }^{1}$ ERIC GRATZ, ${ }^{2}$ ZHANGFENG ZHENG, ${ }^{1}$ \\ QIANG WANG ${ }^{1}$ MENGYUAN CHEN,${ }^{1}$ DIRAN APELIAN,${ }^{1}$ \\ and YAN WANG ${ }^{1,3}$
}

1.-Department of Mechanical Engineering, Center for Resource Recovery and Recycling (CR3), Worcester Polytechnic Institute, 100 Institute Road, Worcester, MA 01609, USA. 2.-Battery Resourcers LLC, 200 Westboro Road, North Grafton, MA 01536, USA. 3.-e-mail: yanwang@wpi.edu

The lithium ion (Li-ion) battery industry has been growing exponentially since its initial inception in the late 20th century. As battery materials evolve, the applications for Li-ion batteries have become even more diverse. To date, the main source of Li-ion battery use varies from consumer portable electronics to electric/hybrid electric vehicles. However, even with the continued rise of Liion battery development and commercialization, the recycling industry is lagging; approximately $95 \%$ of Li-ion batteries are landfilled instead of recycled upon reaching end of life. Industrialized recycling processes are limited and only capable of recovering secondary raw materials, not suitable for direct reuse in new batteries. Most technologies are also reliant on high concentrations of cobalt to be profitable, and intense battery sortation is necessary prior to processing. For this reason, it is critical that a new recycling process be commercialized that is capable of recovering more valuable materials at a higher efficiency. A new technology has been developed by the researchers at Worcester Polytechnic Institute which is capable of recovering $\mathrm{LiNi}_{x} \mathrm{Mn}_{y} \mathrm{Co}_{z} \mathrm{O}_{2}$ cathode material from a hydrometallurgical process, making the recycling system as a whole more economically viable. By implementing a flexible recycling system that is closed-loop, recycling of $\mathrm{Li}$-ion batteries will become more prevalent saving millions of pounds of batteries from entering the waste stream each year.

\section{INTRODUCTION}

Lithium ion (Li-ion) batteries are a very important member of the rechargeable battery family, due to their high discharge voltage, high volumetric and gravimetric energy density, and long cycle life. A typical Li-ion battery consists of an intercalated lithium compound as the cathode and graphite as the anode. The electrolyte supplies the ionic channel for lithium ions transferring between the cathode and anode. Cathode acts as the source of lithium ions while the anode initially contains no Li-ions. ${ }^{1}$ In the history of lithium battery development, the Li-ion battery was derived from the lithium metal battery.

In 1972, Whittingham at Exxon reported the first lithium metal battery with $\mathrm{TiS}_{2}$ as the cathode, lithium metal as the anode, and lithium perchlorate in dioxolane as the electrolyte, since $\mathrm{TiS}_{2}$ was the best intercalation compound available at that time. ${ }^{2}$ However, the progress of this system was hindered by dendritic growth of lithium during cycling of the lithium metal. Later on, lithium alloy ${ }^{3}$ was considered as a substitute for lithium metal to solve the dendrite issue. However the volume swing caused by lithium intercalation/deintercalation led to poor cyclability. To circumvent the safety issue, the insertion materials that could accept Li-ions were simultaneously adopted as the cathode and anode by Murphy et al. ${ }^{4}$ and then by Lazzari and Scrosati ${ }^{5}$ which led to the first Li-ion battery technology at the end of the 1980s and early 1990s.

In the next stage of Li-ion battery advancement, a lithium-oxide material was used as the cathode when it was discovered that oxides permitted 
suitable lithium intercalation. ${ }^{6}$ Later on, a framework structure $\left(\mathrm{V}_{6} \mathrm{O}_{13}\right)$ proved to be an excellent electrode material for $\mathrm{Li}$ intercalation. ${ }^{7}$

Goodenough proposed a better solution for cathode chemistry using the formula $\mathrm{Li}_{x} \mathrm{MO}_{2}(\mathrm{M}=\mathrm{Co}$, $\mathrm{Ni}$ or Mn). This family of cathodes is widely used in modern Li-ion batteries. ${ }^{8-10}$ In 1991, the Sony Corporation commercialized the first Li-ion battery composed of $\mathrm{LiCoO}_{2}$ as the cathode and carbon as the anode. ${ }^{11}$ For safety and capacity reasons, Ni and other metals, such as $\mathrm{Al}, \mathrm{Ga}, \mathrm{Mg}$ or $\mathrm{Ti}$, were applied as a cation substitute for Co. For example, $\mathrm{LiNi}_{1-x} \mathrm{Ti}_{x / 2} \mathrm{Mg}_{x / 2} \mathrm{O}_{2}$ was claimed to be safer and has a specific capacity of $180 \mathrm{mAh} \mathrm{g}^{-1}$ compared to $\mathrm{LiCoO}_{2}$ which has a specific capacity of $140 \mathrm{mAh} \mathrm{g}^{-1}{ }^{12}$ In 1996 , Goodenough et al. proposed lithium iron phosphate as a cathode alternative and Chiang et al. improved the material's performance in 2002 by doping the material with aluminum, niobium and zirconium. ${ }^{13} \mathrm{LiFePO}_{4}$ has an olivine (magnesium iron silicate) oxyanion scaffolded structure, which possesses M-O-X bonds. This structure attracted significant interest, since the transition-metal redox potentials can be altered by the presence of $\mathrm{X} .^{14}$

The anode material has also evolved over time. Research efforts have been focused on materials with higher capacity and slightly more positive intercalation voltages compared to $\mathrm{Li}^{+} / \mathrm{Li}$. $\mathrm{Li}_{3-x-}$ $\mathrm{Co}_{x} \mathrm{~N}$ has a stable and reversible capacity of $600 \mathrm{mAh} \mathrm{g}^{-1} \cdot{ }^{15}$ In 1997 , Idota et al. commercialized a new Li-ion technology by using an amorphous tin composite oxide as the anode. ${ }^{16}$ In the Sn-Fe-C system, ${ }^{17}$ intermetallic alloys, such as $\mathrm{Cu}_{6} \mathrm{Sn}_{5}, \mathrm{InSb}$ and $\mathrm{Cu}_{2} \mathrm{Sb}$, revealed an appealing low voltage and reversible reactivity. ${ }^{18}$ The Li-ion storage mechanism of $\mathrm{MO}(\mathrm{M}=\mathrm{Co}, \mathrm{Ni}, \mathrm{Fe}, \mathrm{Cu}$ or $\mathrm{Mn})$ was reinvestigated by Poizot et al. ${ }^{19}$ Due to its high capacity, $\mathrm{Si}$ is a promising anode material, which has drawn wide attention from both industry and academia. ${ }^{20-22}$

Since the inception of the commercial Li-ion batteries in 1991, the market size has increased exponentially, especially in portable consumer electronics. In 2014, there were over 1500 million cell phones in use powered by Li-ion batteries, up from less than 300 million in $2000 .^{23}$ The current overall Li-ion battery market has reached over US\$20 billion. ${ }^{23}$

In addition, Li-ion batteries have since 2010 been gradually used in larger size systems such as hybrid and electric vehicles due to higher power and energy density. ${ }^{24-26}$ With 2.72 million HEVs/ PHEVs/EVs being sold in 2015, the current Li-ion batteries market in the automotive industry has reached over $\$ 5$ billion. ${ }^{23}$ Because of the global growth of Li-ion batteries used in the automotive industry over the last 5 years, it is estimated that the global market for electric vehicles will reach $\$ 25$ billion by $2025 .^{27}$

\section{MATERIALS USED IN LI-ION BATTERIES}

Li-ion batteries are mainly composed of four parts: cathode, anode, electrolyte, and separator. Electrodes consist of particulate active material, carbon conductive additive, polymeric binder, and current collector. Carbon conductive additives are necessary to provide sufficient electron transport to the site of lithium intercalation in electrode. ${ }^{28}$ When the mass fraction of the additives (such as carbon spheres, carbon black, carbon fibers, and carbon tubes) is sufficiently high and exceeds the percolation threshold ${ }^{29}$ there is enough carbon to form a connected, percolating network throughout the electrode. Polyvinylidene difluoride (PVDF) is widely used as the binder, ${ }^{30}$ but environmentally friendly binders such as carboxymethyl cellulose (CMC) or styrene butadiene rubber (SBR) are gradually replacing PVDF. ${ }^{31,32}$ Aluminum, abundantly available and a light metal, is used as the current collector for the cathode because it forms a passivation layer to inhibit oxidative corrosion. However, it alloys with lithium at low potentials, excluding its use as an anode current collector, for which copper is used instead.

\section{Active Materials}

Extensive investigation on Li-ion batteries has revealed a range of possible active materials. There are different mechanisms behind lithium uptake and release. These mechanisms include: (1) intercalation into a crystalline host (such as in lithium cobalt oxide, (2) electroplating (lithium metal), (3) alloying with metals (such as with silicon ${ }^{33}$ ), (4) conversion reaction, ${ }^{34}$ and (5) other types of insertion such as in amorphous carbon. Among them, several have been already commercialized or are under development.

Graphite is extensively used as the anode material. ${ }^{35}$ Graphite exhibits a low interaction potential, and has a high specific capacity. Lithium titanate $\left(\mathrm{Li}_{4} \mathrm{Ti}_{5} \mathrm{O}_{12}\right.$, LTO) has a relatively low energy density, but works in electrochemical windows in which the organic electrolyte is perfectly stable, resulting in no formation of SEI and no irreversible charge losses during lithium intercalation, which leads to long cycle life. ${ }^{36}$

Lithium cobalt oxide (LCO) was used in the first successfully commercialized Li-ion batteries. To reduce the cost of $\mathrm{LCO}$, the cobalt is often replaced by ternary transition metals changing the composition to $\mathrm{LiNi}_{x} \mathrm{Co}_{y} \mathrm{Mn}_{z} \mathrm{O}_{2}$ with $x, y$ and $z$ close to $0.33 .^{37}$ These layered nickel-manganese-cobalt (NMC) oxides have a slightly lower energy density but superior power density and cycle life compared to LCO. ${ }^{38}$ The properties of NMC can be fine-tuned by changing the composition. Lithium iron phosphate $(\mathrm{LiFePO}, \mathrm{LFP})$ suggested by Padhi and Goodenough, and lithium manganese oxide $\left(\mathrm{LiMn}_{2} \mathrm{O}_{4}\right.$, LMO) suggested by Thackeray and Goodenough derive from inexpensive raw materials which render LFP and LMO batteries attractive for electric 
vehicles. ${ }^{10,14}$ LFP and LMO have relatively low energy densities. Recently, lithium nickel cobalt aluminum oxide (NCA) was developed for electrical vehicles because of its high energy density and long cycle life. ${ }^{39}$ Selecting anode and cathode materials depends on which desired properties are more needed for the specific application. Certain electrochemical properties include energy density, power density, cycle life, safety and cost.

\section{Electrolyte}

The electrolyte has a significant impact on battery performance. The rate capability, cycle life, coulombic efficiency, operation temperature range and safety of Li-ion batteries are mostly determined by the electrolyte composition. The two main components of liquid electrolytes are salt and solvent. Although a few salts such as $\mathrm{LiPF}_{6}, \mathrm{LiClO}_{4}, \mathrm{LiAsF}_{6}$ and $\mathrm{LiBF}_{4}$ have been explored for batteries, $\mathrm{LiPF}_{6}$ is used for commercial systems due to its non-toxicity and thermal stability. ${ }^{40}$ The solvent is composed of mixtures of alkyl carbonates, such as ethylene carbonate (EC), propylene carbonate (PC), ${ }^{41}$ dimethyl carbonate (DMC) and diethyl carbonate (DEC). ${ }^{42,43}$ In addition, electrolyte additives, such as vinylidene carbonate (VC), ${ }^{44}$ are added to improve the cycle life and safety of Li-ion batteries.

\section{Separator}

The separator is a critical component in Li-ion batteries, serving two purposes: (1) to prevent physical contact of the electrodes and to avoid internal short circuiting; and (2) to provide an ionic conduction path for the liquid electrolyte. Porous polyolefin membranes as separators have been most widely used in Li-ion batteries with liquid electrolyte because of their comprehensive advantages of performance, safety and cost. ${ }^{45,46}$ The polyolefin includes polyethylene (PE), ${ }^{47}$ polypropylene $(\mathrm{PP})^{48}$ and their blends such as PE-PP ${ }^{49}$ and high density polyethylene (HDPE)-ultrahigh molecular polyethylene (UHMWPE). ${ }^{50}$ Recently, a ceramic separator for better mechanical and thermal stability has been developed and commercialized. ${ }^{51}$

\section{NEED FOR RECOVERY AND RECYCLING}

Though Li-ion battery recycling rates trail many other common materials and goods, the irony is that lead acid batteries have almost a 99\% recycling rate. ${ }^{52}$ There are several reasons for the latter, and most importantly there exist government regulations requiring recycling of lead acid batteries because lead is toxic. Additionally, lead acid batteries have only one chemistry factor making them simple and economically effective to recycle. Moreover, there is a successful business model for the recycling of lead acid batteries. Collection centers and recovery technologies are in place. One of the key lessons is that solutions for sustainability need to have sustainable business models.

Unfortunately, there is limited economical upside to recycle Li-ion batteries in today's commercialized technologies. This is due to the fact that current industrial recycling processes depend on recovering cobalt and nickel metals or their alloys. Although there are a variety of cathode chemistries and sortation based on chemistry which is challenging and difficult, the incoming recycling stream is often diluted with other metals. Only California, Minnesota and New York have regulations requiring Liion batteries to be recycled, ${ }^{53}$ but enforcement of these laws is not strict and rarely enforced. As early as 2006, it was shown that significant Li-ion battery stockpiles had begun building up in developed countries. ${ }^{54}$ Unfortunately, there are no up-to-date numbers for the recycling rate in North America, while in Europe, before regulation was imposed, the recycling rate was only $9 \%{ }^{55}$

An estimation of the total amount of Li-ion batteries recycled in North America can be made by tracking the number and recycling rate of ewaste devices, specifically those devices that use Liion batteries. When an e-waste device is recycled, it is often recycled with the battery and the battery is sent to a separate recycler for recycling. This number serves as an estimate and will not include every Li-ion battery recycled in North America.

Table I shows that a minimum estimate for the amount of Li-ion batteries recycled in North America is 5569 tons with the majority of the battery mass coming from laptops. The estimated volume matches up well with the masses of Li-ion batteries recycled by current commercial operations (see next section). However, assuming North American market share of $31 \%$ and an average Li-ion battery gets US $\$ 300 / \mathrm{kWh}$ then the actually recycling rate is only $3 \%,{ }^{23}$ which means that the Li-ion battery recycling industry is dominated by laptop batteries. The reason for this is that the laptop batteries are the

Table I. Estimated annual tons of Li-ion batteries recycled in North America

\begin{tabular}{|c|c|c|c|c|c|}
\hline & \# in NA (million) & Rate (\%) & \# recycled (million) & Average battery mass (g) & Mass recycled (tons) \\
\hline Cell phones & $140-170$ & $14-17^{56}$ & $14-17$ & $22^{57}$ & $308-374$ \\
\hline Laptops & $45^{58}$ & $40^{59}$ & 18 & 278.4 & 5011 \\
\hline Tablets & 23 & 10 & 2.3 & 50 & 250 \\
\hline Total & & & & & 5569 \\
\hline
\end{tabular}


heaviest and have the highest recycling rate. Cell phones, on the other hand, are the most used but are recycled less frequently and therefore have a lower mass. As a result of the low recycling rate, the majority of Li-ion batteries are landfilled. With the wide adoption of hybrid and pure electric vehicles, this situation will become even worse. This creates environmental concerns. For example, when left unattended, Li-ion batteries in landfills may catch fire or, if the electrolyte is exposed to water, hydrogen fluoride formation can occur. ${ }^{60}$ Additionally, lithium may enter the ground water. ${ }^{61}$ All of these are non-options for a sustainable future.

\section{CURRENT INDUSTRIAL RECYCLING TECHNOLOGIES}

Li-ion batteries are being recycled commercially to extract valuable raw materials and to safely dispose of a hazardous waste. Several companies have developed predominately in North America and Europe to handle the flux of end-of-life batteries entering the waste stream every year (Table II). The majority of Li-ion batteries come from consumer electronics and electric/hybrid electric vehicles. The two major mechanisms for Li-ion battery recycling are pyrometallurgical and hydrometallurgical processes. Pyrometallurgical treatment uses high temperature smelting procedures to recover cobalt and nickel as alloys. Hydrometallurgical techniques use chemical leaching to facilitate materials recovery.

\section{RECOVERY OF LI-ION BATTERIES}

Li-ion batteries have seen increasing interest in their recovery for second life applications. This is particularly true for Li-ion batteries used in hybrid electric vehicle/electric vehicle (HEV/EV) applications where the battery is considered no longer suitable for the vehicle when it reaches $80 \%$ of its original capacity. These second-life batteries are seeing much interest in being used as grid-level storage devices. ${ }^{65,66}$ Additionally, there is interest in using Li-ion batteries in EVs for vehicle to grid (V2G) integration. In V2G integration, the EV communicates with the grid (i.e., smart grid) whether the battery will charge or discharge based on the grid's power demands and the price of energy. Both scenarios of grid-level adaption of EV batteries will have the most benefit in their ability to help the grid meet high power pulses or load fluctuations. These deviations from base-level grid demands are estimated to cost the US between 5\% and $10 \%$ of its total electrical demand. ${ }^{65}$ Although not currently mainstream, second-life use for EV/ HEV Li-ion batteries is a likely outcome for many batteries. Since most EV/HEV batteries have not reached their end of life, the percentage of batteries that will be suitable for second-life applications is unknown. Navigant predicts the second-life battery vehicle market to grow from $\$ 16$ million in 2014 to

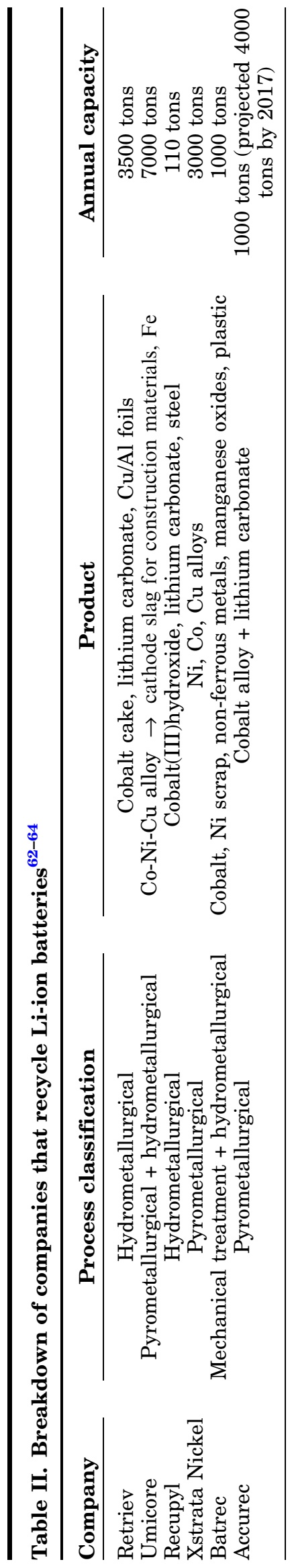


$\$ 3$ billion by $2035 .{ }^{67}$ While second life is a promising scenario for end-of-life batteries, ultimately these batteries will also have to be recycled.

\section{LI-ION BATTERY RECYCLING IN OUR GROUP}

Although different Li-ion battery recycling processes have been commercialized, most of the processes cannot handle mixed cathode chemistry or only low valle materials are recycled. A new Li-ion battery recycling process invented by Wang et al. ${ }^{68}$ at Worcester Polytechnic Institute (WPI) to recycle Li-ion batteries regardless the battery size, shape or cathode chemistry directly synthesizes new cathode materials. This process is being commercialized by Battery Resources, LLC (BR). BR uses a mixed physical and hydrometallurgical process to directly synthesis new active $\mathrm{LiNi}_{x} \mathrm{Mn}_{y} \mathrm{Co}_{z} \mathrm{O}_{2}(x+y+z=1)$ cathode materials. Additionally, steel, copper, aluminum, graphite and plastics are also recovered. The synthesis of new active cathode materials as well as the overall recycling process has been published previously ${ }^{68-70}$ The major advantages of the $\mathrm{BR}$ recycling process are that it can handle any Li-ion battery regardless of size, shape or cathode chemistry, and recovers active cathode material which accounts for over $70 \%$ of the battery value. ${ }^{68}$ Thus, the process has significant economic advantages over traditional recycling processes, where only the metal value is recovered.

By combining both physical and hydrometallurgical processes, BR is able to recover all of the elements of the Li-ion battery with the exception of the electrolyte and solvent (lithium from $\mathrm{LiPF}_{6}$ is recovered in the lithium recovery step). ${ }^{68}$ The only material lost in the recycling process occurs due to impurity removal; additionally, at the end of the process, there is wastewater from the hydrometallurgical process that must be disposed of. In total, over $70 \%$ of the battery weight accounting for inefficiencies can be recovered. Additionally, because there are no pyrometallurgical steps, there are no direct carbon emissions from the recycling process.

One major advantage of the BR process is the ability to handle any type of Li-ion battery. While the first Li-ion batteries used only $\mathrm{LiCoO}_{2}$, in the current market, the cathode material used in Li-ion batteries is changing every year. In 2008 , over $60 \%$ of Li-ion batteries used $\mathrm{LiCoO}_{2}$ cathode materials; however, by 2012 , that number has dropped to only $37.2 \%$ (Table III). That value is also expected to drop to $25 \%$ by $2020 .^{23}$ The decrease in Co is also evident in the recycling stream. The composition of the incoming recycling stream is expected to trail the current market composition by 3-4 years due to the lifetime of the batteries. The amount of $\mathrm{Co}, \mathrm{Ni}$, and $\mathrm{Mn}$ present in Li-ion batteries collected from the WPI recycling bins show that, in 2012, Co made up over $90 \%$ of the transition metals present, and by 2014 that number had decreased to less than $60 \%$ (Table IV).

The performance of the recovered $\mathrm{LiNi}_{1 / 3} \mathrm{Mn}_{1 /}$ ${ }_{3} \mathrm{Co}_{1 / 3} \mathrm{O}_{2}$ from recycled batteries has been tested at both WPI and Argonne National Laboratory. The material characterization and electrochemical performance shows that the recovered material is very similar to the commercial material. The cathode materials where spherical and $\sim 10 \mu \mathrm{m}$ in diameter, with a capacity greater than $150 \mathrm{~mA} \mathrm{~g}^{-1}$ as tested at both WPI and Argonne. ${ }^{72}$ As previously reported, 1 ton of spent Li-ion batteries has the potential to generate over $\$ 6000$ in revenue when the active cathode material, steel, copper, and aluminum are recovered. ${ }^{68}$

\section{FUTURE PROSPECTS AND IMPLICATIONS}

Today, millions of pounds of Li-ion batteries are landfilled instead of recycled each year, depleting natural resources like cobalt, nickel, and lithium. Large-scale recycling directly equates to a more sustainable, cyclic society, one that recovers materials instead of disposing of them. Li-ion battery recycling has not become more prevalent for three reasons. (1) Current commercialized technologies are limited and do not draw a large enough profit margin to substantiate growth. For the most part, the products of recycling processes are less valuable than the batteries being processed and not all valuable components of the battery are being recovered. The business model for current recycling technologies is not robust; (2) The cathode chemistries of Li-ion batteries are constantly evolving, making it difficult

Table IV. Ratio of nickel, cobalt and manganese in batteries recovered from WPI's recycling centers

\begin{tabular}{lccc}
\hline Year & \%Co & $\frac{\% \mathbf{N i}}{6}$ & $\frac{\% \mathbf{M n}}{4}$ \\
2012 & 90 & 6 & 15 \\
2014 & 60 & 25 & \\
\hline
\end{tabular}

Table III. World market size of different cathode materials

\begin{tabular}{|c|c|c|c|c|c|}
\hline Year & $\underline{\mathrm{LiNi}_{0.33} \mathrm{Mn}_{0.33} \mathrm{Co}_{0.33} \mathrm{O}_{2}(\%)}$ & $\mathrm{LiCoO}_{2}(\%)$ & $\operatorname{LiMn}_{2} \mathbf{O}_{4}(\%)$ & $\mathrm{LiFePO}_{4}(\%)$ & $\mathrm{LiNiO}_{2} / \mathrm{LiNiCoAlO}_{2}(\%)$ \\
\hline $2008^{71}$ & 18.9 & 60.8 & 10.5 & 3.5 & 6.5 \\
\hline $2012^{71}$ & 29.00 & 37.2 & 21.40 & 5.2 & 7.2 \\
\hline $2014^{23}$ & 31.0 & 39.8 & 15.9 & 8.8 & 4.5 \\
\hline
\end{tabular}


for recycling companies to adapt. And (3), although end-of-life Li-ion batteries are characterized as hazardous, in many countries government mandates do not exist that would force recycling.

To cope with the increasing number of Li-ion batteries being used in various technologies, ${ }^{73}$ a recovery process must be implemented at an industrial scale that is economically viable now and in the future. One solution is to develop a recycling system that is completely closed-looped. The cathode material is significantly more valuable than all other components that make up a Li-ion battery. An ideal technology could process any type of Li-ion battery and recover the cathode instead of secondary raw materials that require further processing to make new active materials.

It is the responsibility of engineering leaders to manufacture products that can be recovered at the end of life and reused. How components are assembled and how they can be disassembled and recovered ought to be considered at the initial stages of design. At present, we are addressing recovery and recycling as an afterthought. The closed-loop mindset and manufacturing for disassembly should be considerations from day one. Today, we are using most of the Periodic Table to manufacture the components that our society consumes. These elements are not renewable resources, and the materials community has a responsibility to ensure that we recover and reuse them at their end of life.

A more robust recycling system would provide the outlet necessary to handle the flux of spent Li-ion batteries facilitated by the rapid growth of the electric and hybrid-electric vehicle market. With the projected growth of future Li-ion battery use increasing exponentially, it is critical that the recycling market also react congruently. Although different Li-ion battery recycling processes are being commercialized in Europe and America, these technologies cannot adapt to the changes of cathode materials in Li-ion batteries and/or produce highvalle materials. The recycling technology developed at WPI and BR offers a closed-loop Li-ion battery recycling process with the ability to recycle Li-ion batteries of any size, shape and chemistry.

\section{ACKNOWLEDGEMENTS}

This work has been financially supported by the National Science Foundation (NSF) under Grants 1230675, 1343439, 1464535 and 1549531, and WPI's Center for Resource Recovery and Recycling (CR3 an NSF I/UCRC).

\section{REFERENCES}

1. J.M. Tarascon and M. Armand, Nature 414, 359 (2001).

2. M. Whittingham, Science 192, 1126 (1976).

3. B.M.L. Rao, R.W. Francis, and H.A. Christopher, J. Electrochem. Soc. 124, 1490 (1977)

4. D. Murphy, F.J. Di Salvo, J.N. Carides, and J. Waszczak, Mater. Res. Bull. 13, 1395 (1978).

5. M. Lazzari and B. Scrosati, J. Electrochem. Soc. 127, 773 (1980).
6. J. Broahead and A. Butherus, Rechargeable nonaqueous battery, Google Patents (1974). https://www.google.com/pa tents/US3791867?dq=US3791867\&hl=en\&sa=X\&ved=0ah UKEwjL-Zedmt3MAhVBRyYKHWW7CFsQ6AEIHTAA. Accessed March 2016.

7. D.W. Murphy, Science 205, 651 (1979).

8. K. Mizushima, P.C. Jones, P.J. Wiseman, and J.B. Goodenough, Mater. Res. Bull. 15, 783 (1980).

9. K. Mizushima, Solid State Ion. 3, 171 (1981).

10. M. Thackeray, W. David, P. Bruce, and J.B. Goodenough, Mater. Res. Bull. 18, 461 (1983).

11. T. Nagaura and K. Tozawa, Prog. Batter. Solar Cells 9, 209 (1990).

12. Y.A. Gao, M.V. Yakovleva, and W.B. Ebner, Electrochem. Solid State Lett. 1, 117 (1998).

13. S.Y. Chung, J.T. Bloking, and Y.M. Chiang, Nat. Mater. 1, 123 (2002)

14. A.K. Padhi, K.S. Nanjundaswamy, C. Masquelier, S. Okada, and J.B. Goodenough, J. Electrochem. Soc. 144, 1609 (1997).

15. T. Shodai, S. Okada, S.I. Tobishima, and J.I. Yamaki, Solid State Ion. 86, 785 (1996).

16. Y. Idota, T. Kubota, A. Matsufuji, Y. Maekawa, and T. Miyasaka, Science 276, 1395 (1997).

17. O. Mao, R.A. Dunlap, and J.R. Dahn, J. Electrochem. Soc. 146, 405 (1999)

18. K.D. Kepler, J.T. Vaughey, and M.M. Thackeray, Electrochem. Solid State Lett. 2,7 (1999).

19. P. Poizot, S. Laruelle, S. Grugeon, L. Dupont, and J.-M. Tarascon, Nature 407, 496 (2000).

20. Y. Zhou, H. Guo, Y. Yang, Z. Wang, X. Li, R. Zhou, and W. Peng, Mater. Lett. 168, 138 (2016).

21. R. Zhou, R. Fan, Z. Tian, Y. Zhou, H. Guo, L. Kou, and D. Zhang, J. Alloys Compd. 658, 91 (2016).

22. M. Ashuri, Q.R. He, and L.L. Shaw, Nanoscale 8, 74 (2016).

23. C. Pillot, "Battery Market Development for Consumer Electronics, Automotive, and Industrial: Materials Requirements and Trends" (avicenne, 2015), http://www. avicenne.com. Accessed February 2006.

24. L. Gaines, Sustain. Mater. Technol. 1-2, 2 (2014).

25. M. Broussely and D. MacArthur, Lithium Batteries: Science and Technology, 1st ed. (Boston: Springer, 2003), p. 645 .

26. M. Broussely and D. MacArthur, Lithium Batteries: Science and Technology, 1st ed. (Boston: Springer, 2003), p. 701.

27. M. Lowe, "Lithium-Ion Batteries for Electric Vehicles: The US Value Chain" (Duke University, 2010), http://millen niumindicators.un.org/unsd/trade/s_geneva2011/refdocs/ RDs/Lithium-Ion\%20Batteries\%20(Gereffi\%20-\%20May\% 202010).pdf. Accessed March 2016.

28. M. Park, X. Zhang, M. Chung, G.B. Less, and A.M. Sastry, J. Power Sources 195, 7904 (2010).

29. S. Munson-McGee, Phys. Rev. B 43, 3331 (1991).

30. B. Lestriez, C. R. Chim. 13, 1341 (2010).

31. J.H. Lee, U. Paik, V. Hackley, and Y.M. Choi, J. Electrochem. Soc. 152, A1763 (2005).

32. H. Yamamoto and H. Mori, Lithium-Ion Batteries, 1st ed. (Boston: Springer, 2009), pp. 163-179.

33. C. Wang, A.J. Appleby, and F.E. Little, J. Power Sources 93, 174 (2001).

34. J. Cabana, L. Monconduit, and D. Larcher, Adv. Energy Mater. 22, E170 (2010).

35. B. Scrosati, J. Solid State Electrochem. 15, 1623 (2011).

36. D. Ahn and X. Xiao, Electrochem. Commun. 13, 796 (2011).

37. Y. Koyama, N. Yabuuchi, I. Tanaka, H. Adachi, and T. Ohzuku, J. Electrochem. Soc. 151, A1545 (2004)

38. N. Yabuuchi, Y. Makimura, and T. Ohzuku, J. Electrochem. Soc. 154, A314 (2007).

39. C.H. Chen, J. Liu, M.E. Stoll, G. Henriksen, D.R. Vissers, and K. Amine, J. Power Sources 128, 278 (2004).

40. K. Xu, Chem. Rev. 104, 4303 (2004).

41. A. Dey and B. Sullivan, J. Electrochem. Soc. 117, 222 (1970). 
42. J. Tarascon and D. Guyomard, Solid State Ion. 69, 293 (1994).

43. D. Aurbach, Y. Ein-Eli, B. Markovsky, A. Zaban, S. Luski, Y. Carmeli, and H. Yamin, J. Electrochem. Soc. 142, 2882 (1995).

44. S.S. Zhang, J. Power Sources 162, 1379 (2006).

45. D. Linden and T.B. Reddy, Handbook of Batteries, 1st ed. (New York: McGrawHill, 2002).

46. J.M. Ko, B.G. Min, D.W. Kim, K.S. Ryu, K.M. Kim, Y.G. Lee, and S.H. Chang, Electrochim. Acta 50, 367 (2004).

47. N. Kaimai, Method of producing highly permeable microporous polyolefin membrane, Google Patents (2000). http:// www.google.com/patents/US6153133. Accessed March 2016.

48. F. Chu and Y. Kimura, Polymer 37, 573 (1996).

49. H. Higuchi, K. Matsushita, M. Ezoe, and T. Shinomura, Porous film, process for producing the same, and use of the same, Google Patents (1995). https://www.google.com/pa tents/US5385777. Accessed March 2016.

50. D. Ihm, J. Noh, and J. Kim, J. Power Sources 109, 388 (2002).

51. S. Augustin, V. Hennige, G. Hijrpel, and C. Hying, Desalination 146, 23 (2002).

52. W. Beck, "Advancing Sustainable Materials Management: Facts and Figures" (US Environmental Protection Agency, 2016), https://www.epa.gov/smm/advancing-sustainablematerials-management-facts-and-figures. Accessed February 2016.

53. V. Bueno, "Advancing Sustainable Materials Management: Facts and Figures" (Call-2-Recycle, 2016), http://www.call2re cycle.org/recycling-law-map/. Accessed February 2016.

54. T.C. Chang, S.J. You, B.S. Yu, and K.F. Yao, J. Hazard. Mater. 163, 910 (2009).

55. T. Georgi-Maschler, B. Friedrich, R. Weyhe, H. Heegn, and M. Rutz, J. Power Sources 207, 173 (2012).

56. P. Anthony, "Cell Phone Recycling By the Numbers" (ecycle, 2013), http://www.e-cycle.com/tag/cell-phone-re cycling-2/. Accessed March 2016.

57. C. Pillot, "The Portable Rechargeable Battery (PRB) Market in Europe (2008-2015)" (Recharge, 2010), http://www. rechargebatteries.org/wpcontent/uploads/2013/04/Portable_ Rechargeable_Battery_Market_in_Europe_2008-2015_-_Jan_ 2011.pdf. Accessed February 2016.

58. G. Hariharan, "PC/Tablet forecasts 2013 hope for touchNBs, cheap tablet proliferation favors components in Asia Pacific Equity Research" (2013).
59. K.A. Smith, S.D. Sheppard, D.W. Johnson, and R. Johnson, J. Eng. Educ. 94, 87 (2005).

60. S.F. Lux, J. Chevalier, I.T. Lucas, and R. Kostecki, ECS Electrochem. Lett. 2, A121 (2013).

61. B. Robinson, Sci. Total Environ. 408, 183 (2009).

62. C. Siret, "EV\&HEV battery developments and prospectives: closed-loop battery recycling" (avnir, 2012), http:// avnir.org/documentation/congres_avnir/telechargements 2012/presentations/SiretLCAconf2012.pdf. Accessed March 2016.

63. A. Chagnes and J. Swiatowska, Lithium Process Chemistry, 1st ed. (Amsterdam: Elsevier, 2015).

64. I. Weyhe, "New Headquarter in Krefeld Permitted" (Accurec, 2016), http://www.accurec.de/ . Accessed February 2016.

65. W. Kempton and J. Tomić, J. Power Sources 144, 268 (2015).

66. B. Dunn, H. Kamath, and J.M. Tarascon, Science 334, 928 (2011).

67. Navigant, "Second-Life Batteries: From PEVs to Stationary Applications" (Navigant Research, 2014), https://www. navigantresearch.com/research/second-life-batteries-frompevs-to-stationary-applications. Accessed March 2016.

68. E. Gratz, Q. Sa, D. Apelian, and Y. Wang, J. Power Sources 262,255 (2014).

69. H. Zou, E. Gratz, D. Apelian, and Y. Wang, Green Chem. 15, 1183 (2013).

70. Q. Sa, E. Gratz, D. Apelian, and Y. Wang, J. Power Sources 282, 140 (2015).

71. L. Gaines, J. Sullivan, A. Burnham, and I. Belharouak, "Life Cycle Analysis for Lithium-Ion Battery Production and Recycling" (Argonne National Laboratory, 2011), https://www.researchgate.net/profile/Linda_Gaines/publication/ 265158823_Paper_No._11-3891_LifeCycle_Analysis_for_Lithiu mIon_Battery_Production_and_Recycling/links/547336180cf21 6f8cfaeb58a.pdf. Accessed March 2016.

72. Q. Sa, E. Gratz, J. Heelan, S. Ma, D. Apelian, and Y. Wang, J. Sustain. Metall. (2016). doi:10.1007/s40831-016-0052-x.

73. L. Gaines and K. Klein, "Reducing Foreign Lithium Dependence through Co-Production of Lithium from Geothermal Brine" (Argonne National Laboratory, 2011), https://anl.app.box.com/s/8jrm6w3d0l1ar8ygc1q68ujirppov wyf. Accessed March 2016. 